senting with a thyroid nodule or goitre is by radioisotope or ultrasound scanning. Thyroid uptake scans with technetium$99 \mathrm{~m}$ or iodine-123 indicate whether a nodule or area of a gland is "hot" or "cold"-that is, whether it takes up the isotope or not. In a review of cases in which all patients underwent operation malignant disease was found in $16 \%$ of cold nodules, $9 \%$ of warm nodules, and $4 \%$ of hot nodules. ${ }^{3}$ Therefore a cold nodule has the greatest probability of being malignant, but most are benign, and finding a hot nodule does not exclude malignancy. The value of isotope scanning is thus limited by its poor differentiation of benign from malignant disease. Similarly, no sonographic criteria can reliably distinguish benign from malignant thyroid tissue. Though ultrasound examination will classify goitres or nodules accurately as being solid, semisolid, or cystic and fewer cystic lesions than solid lesions are malignant, some carcinomas undergo cystic degeneration.

In contrast to these scanning techniques, which give an indirect indication of the nature of the lesion, fine needle aspiration provides a means of obtaining thyroid tissue for direct cytological examination without the need for surgery. The procedure, which is well tolerated and easily performed in an outpatient department, has been used extensively in Scandinavia for over 25 years. A skilled cytologist can achieve excellent diagnostic accuracy. Reviewing published comparisons between cytological and histological findings at surgery in over 3500 patients, Lowhagen et al found that false negative diagnoses occurred in fewer than $10 \%$ of cases and false positive ones in fewer than $2 \%$. $^{+}$Similarly, British experience showed false negative and false positive rates of $6.3 \%$ and $0.6 \%$, respectively, in 373 patients with histological confirmation of the cytological diagnosis.

In our own series of 109 euthyroid patients with thyroid enlargement presenting consecutively to a joint medical and surgical clinic the clinical and cytological diagnosis was of benign colloid goitre in 58 patients. Two patients underwent thyroidectomy because of the size of the goitre; lymphocytic thyroiditis was found in nine patients, six of whom were positive for thyroid antibodies, none being treated surgically. Fluid was aspirated from thyroid cysts in 29 patients, all of whom had solitary nodules clinically; the nodules disappeared after aspiration in 22 cases, seven cysts requiring two aspirations-a "cure rate" of $76 \%$ during the review period. Cytological examination of the cyst fluid showed no malignant cells in any case. Similarly, Edmonds and Tellez report that 11 of 22 simple cysts disappeared after aspiration and that recurrent cysts could be treated successfully with the injection of tetracycline ( $p$ 529).

Suspicious or frankly neoplastic cytological findings were reported in 13 of our 109 patients. Three cytological diagnoses (anaplastic carcinoma, lymphoma, and metastatic oat cell carcinoma of the bronchus) spared the patients surgery, and among 10 patients referred for thyroidectomy follicular, papillary, or medullary tumours were confirmed histologically in seven. One initial false negative cytological report has emerged in a patient with a follicular adenoma during a mean follow up of 16 months.

Fine needle aspiration cytology has replaced radioisotope and ultrasound scanning in our practice; the financial saving for the technetium-99m scans no longer performed is $£ 35$ for every new patient seen with thyroid enlargement. More important, however, is the reduction in the number of operations for removal of non-neoplastic disease, both in our own clinic and in those of others. ${ }^{2+6}$ For example, Al-Sayer $e t$ al found a $25 \%$ reduction in the frequency of operation for isolated thyroid swellings and an increase in the proportion of operations for neoplasia from $31 \%$ to $50 \%$ after they had introduced aspiration cytology. ${ }^{7}$ In our own series neoplastic tissue was removed from $41 \%$ of patients undergoing thyroidectomy compared with a predicted rate of $12 \%$ if all cold or solid lesions had been removed.

The limitations of fine needle aspiration cytology include its inability to distinguish benign from malignant follicular neoplasms-which needs surgical excision to provide a histological diagnosis-and a finite false negative rate, owing largely to sampling error. None the less, in their decision analysis of the management options in patients with thyroid nodules Molitch et al showed that aspiration cytology, followed by selective surgery, results in a lower eventual morbidity and mortality when compared with subtotal thyroidectomy in all patients. ${ }^{8}$ Finally, a further important benefit of fine needle aspiration is the prompt reassurance which the results can often give to both the patient and the doctor.

JAYNE A FRANKLYN Lecturer

Michael C ShePpard Professor

Department of Endocrinology,

Queen Elizabeth Hospital,

Birmingham B15 2TH

1 Tunbridge W'MG. Evered DC. Hall R, el al. The spectrum of thyroid disease in a community: the Whickham survev. Clin Endocrinol 1977;7:481-93.

Rojeski MT. Gharib H. Nodular thuroid disease, evaluation and management. $N$ Engl f. Mid 1985:313:428-36.

Ashcroft MW, Van Herle AJ. Management of thyroid nodules. II. Scanning techniques, thvroid suppressive therapy, and fine needle aspiration. Head Neck Surg 1981:3:297-322.

+ Lowhagen \% Willems JS, Lundell G. Sundblad R. Granberg PO. Aspiration biopsv cytology in the diagnosis of thyroid cancer. W'orld $\mathcal{F}$ Surg 1981:5:61-73.

5 Anderson JB, Webb AJ. Fine-needle aspiration biopsy and the diagnosis of thyroid cancer. Bry S urg 1987:74:292-6.

6 Hamberger B, Gharib H, Melton LJ, Goellnew JR, Zinsmeister AR. Fine needle aspiration biops of thyroid nodules: impact on thyroid practice and cost of care. Am F Med 1982:73:381-4.

Al-Saver HM, Krukowsi ZH, Williams VMM, Matheson NA. Fine needle aspiration cytology in isolated thyroid swellings: a prospective two year evaluation. Br Med f 1985;290:1490-2.

8 Molitch ME, Beck JR, Dreisman M. Gottlicb JE Pauker SG. The cold thyroid nodule: an analvsis of diagnostic and therapeutic options. Endocr Rei' 1984:5:185-99.

\section{AIDS and tuberculosis}

Highly pathogenic organisms, such as Mycobacterium tuberculosis, may infect patients with the acquired immune deficiency syndrome (AIDS) or the AIDS related complex early in the disease, before immune deficiency has fully developed.' In contrast, organisms of low virulence, such as $M$ avium-intracellulare, strike later when immune deficiency has fully developed. Tuberculosis may thus precede AIDS by several months-as occurred in 14 of 29 cases reported from New Jersey ${ }^{2}$ and in 18 of 30 cases from New York - but often the two conditions are diagnosed concurrently.

The risk of a patient with AIDS acquiring tuberculosis depends on the prevalence of the disease in the local population. Thus in one series 27 of 45 patients with AIDS who came from Haiti, where tuberculosis is common, were infected with $M$ tuberculosis compared with only one of 37 non-Haitians. ${ }^{+}$In parts of central Africa where AIDS has become epidemic there is also a high rate of associated tuberculosis.'

Intravenous drug abusers appear to be at special risk of acquiring tuberculosis, and a high rate of infection in this group was reported well before AIDS began." This 
special susceptibility may result partly from environmental factors and partly from drug induced impairment of cellular immunity.' AIDS thus compounds the risk of acquiring tuberculosis, and in the United States most patients with AIDS and tuberculosis have been drug abusers. ${ }^{238}$

The clinical manifestations of tuberculosis in patients with AIDS are varied and often atypical. Fever, fatigue, and weight loss are features of both conditions and not specific to either. The lungs are less often affected than other parts of the body, and the disease may become widely disseminated. ${ }^{9}$ Tuberculous lymphadenopathy is common and cannot be distinguished clinically from the lymphadenopathy of AIDS or the AIDS related complex. Other common sites of infection are the blood, bone marrow, genitourinary tract, liver, and peritoneum; the central nervous system may be affected by tuberculomas, cerebral abscesses, or tuberculous meningitis. ${ }^{10}$

The radiological pattern of pulmonary tuberculosis in patients with AIDS is often atypical ${ }^{11}$ : hilar or mediastinal lymph node enlargement is common; the middle or lower lobes are often affected while the upper lobes are spared; and cavitation is rare. Diagnosis depends on bacteriological examination of the sputum, induced if necessary by inhaling nebulised saline. ${ }^{12}$ When the sputum smear shows no bacilli bronchoscopy should be done and specimens obtained for bacteriological examination by bronchoalveolar lavage and transbronchial biopsy. The tuberculin skin test has limited value in diagnosis. About $40 \%$ of cases show a positive response, ${ }^{+}$but the reaction is usually weak and often becomes negative within a few months. If the search for tubercle bacilli is negative the diagnosis of extrapulmonary tuberculosis depends on pathological examination of suitable biopsy specimens, especially of lymph nodes. Granuloma formation is, however, often scanty or absent, and the lesions are depleted in lymphocytes; these features are characteristic of "areactive" tuberculosis.

The limited published information on treating patients with tuberculosis and AIDS shows that standard regimens of antituberculosis drugs are satisfactory, ${ }^{28}$ and in most patients with pulmonary disease the bacilli disappear from sputum in one to three months. The optimum duration of treatment has not been determined, but short course chemotherapy is unlikely to be adequate; courses of at least nine months are usually given' and in some cases are followed by daily isoniazid to prevent relapse. Hypersensitivity reactions to drugs are common in AIDS $^{13}$; they are encountered in patients treated with co-trimoxazole for infection with Pneumocystis carinii, ${ }^{14}$ and similar reactions might be expected to antituberculosis drugs. In patients who are likely to be on concurrent treatment for other infections or complications of AIDS identifying the cause of a drug reaction may be difficult. Multiple treatment also presents the risk of adverse interaction between drugs, and in one reported case interaction between ketoconazole (given for candidiasis) and rifampicin led to low serum concentrations of rifampicin. ${ }^{15}$

Until recently tuberculous infection in AIDS was not regarded as common, but American reports show an increasing incidence of tuberculosis among patients with AIDS, especially those in urban areas such as New York and New Jersey, where drug abuse is common. As Britain is likely to follow this trend, ${ }^{16}$ assiduous screening for tuberculosis is essential, and perhaps high risk subjects should be given prophylaxis with daily isoniazid. ${ }^{17} \mathrm{~A}$ drug abuser infected with the human immunodeficiency virus and with a positive tuberculin skin test might qualify for chemo- prophylaxis, but its efficacy for this type of case has yet to be assessed.

K P GOLDMAN

Consultant Chest Physician,

West Hill Hospital,

Dartford,

Kent DA1 2HF

1 Pinching AJ. The acquired immune deficiency syndrome: with special reference to tuberculosis. Tubercle 1987;68:65-9.

2 Sunderam G, McDonald J, Maniatis T, Oleske J, Kapila R, Reichman LB. Tuberculosis as a manifestation of the acquired immune deficiency syndrome (AIDS). JAMA 1986;256:362-6. Handwerger S, Mildvan D, Senie R, McKinley FW. Tuberculosis and the acquired immunodeficiency syndrome at a New York City hospital: 1978-1985. Chest 1987;91:176-80.

4 Pitchenik AE, Cole C, Russell BW, Fischl MA, Spira TJ, Snider DE. Tuberculosis, atypical mycobacteriosis and the acquired immunodeficiency syndrome among Haitian and non-Haitian patients in south Florida. Ann Intern Med 1984;101:641-5.

Biggar RJ. The clinical features of HIV infection in Africa. Br Med f 1986;293:1453-4.

6 Reichman LB, Felton CP, Edsall JR. Drug dependence, a possible new risk factor for tuberculosis disease. Arch Intern Med 1979;139:337-9.

Brown SM, Stimmel B, Taub RN. Immunologic dysfunction in heroin addicts. Arch Intern Med 1974;134:1001-3.

8 Duncanson FP, Hewlett D Jr, Maayan S, et al. Mycobacterium tuberculosis infection in the acquired immunodeficiency syndrome. A review of 14 patients. Tubercle 1986;67:295-302.

9 Centers for Disease Control. Diagnosis and management of mycobacterial infection and disease in persons with human immunodeficiency virus infection. Ann Intern Med 1987;106:254-6.

10 Bishburg E, Suderam G, Reichman LB, Kapila R. Central nervous system tuberculosis with the acquired immunodeficiency syndrome and its related complex. Ann Intern Med 1986;105:210-3.

11 Pitchenik AE, Rubinson HA. The radiographic appearance of tuberculosis in patients with the acquired immune deficiency syndrome (AIDS) and pre-AIDS. Am Rev Respir Dis 1985;131: 393-6.

12 Luce JM. Sputum induction in the acquired immunodeficiency syndrome. Am Rev Respir Dis 1986;133:513-4

13 Gordin MF, Simon GL, Wofry CB, Mills J. Adverse reactions to trimethoprim-sulphamethoxazole in patients with the acquired immunodeficiency syndrome. Ann Intern Med 1984;100:495-9.

14 Doble N, Hykin P, Shaw R, Keal EE. Pulmonary mycobacterium tuberculosis in the acquired immunodeficiency syndrome. BrMed $\mathcal{F}$ 1985;291:849-50.

15 Robertson JR, Bucknall ABV, Welsby PD, et al. Epidemic of AIDS related virus (HTLV-111/ LAV) infection among intravenous drug users. BrMed $\mathcal{F}$ 1986;292:527-9.

16 Bailey WC, Byrd RB, Glassroth JC, et al. National consensus conference on tuberculosis: preventive treatment of tuberculosis. Chest 1985;87(suppl):128-32.

\section{Insights from radiation treatment for benign disease}

One way that we have of studying the effects of low level ionising radiation is to follow up patients treated with radiation for benign disease between the 1920s and 1950s. Thus epilation with $x$ rays for ringworm resulted in an excess of carcinoma of the skin and thyroid, ${ }^{1}$ and thyroid carcinoma was also an important complication of radiotherapy for benign enlarged thymus glands. ${ }^{2} \mathrm{~A}$ threefold increase in leukaemia mortality in England and Wales between 1930 and 1955 together with the early reports of leukaemia in those who had survived the atom bomb and in patients treated with radiotherapy for ankylosing spondylitis prompted the initial study by Court Brown and Doll of over 14000 patients given radiotherapy for ankylosing spondylitis between 1935 and 1954. ${ }^{3}$ They showed an increased risk of leukaemia and other cancers, and a new report from Doll and others now presents the long term follow up on 14106 of those patients who were given a single course of $x$ ray treatment. ${ }^{4}$

There was a threefold increase in mortality from leukaemia in those irradiated compared with the general population. Mortality from neoplasms other than leukaemia or colonic cancer was also $28 \%$ higher. Both increases were thought to be caused by the previous radiotherapy, whereas the $30 \%$ increase in deaths from colonic cancer and the $51 \%$ increase in deaths from non-neoplastic disease were thought to be related to the ankylosing spondylitis and its association with other secondary diseases such as ulcerative colitis. The relative risk for leukaemia was highest between 2.5 and 4.9 years after the treatment but was still almost double that 